(كو, الاهنا
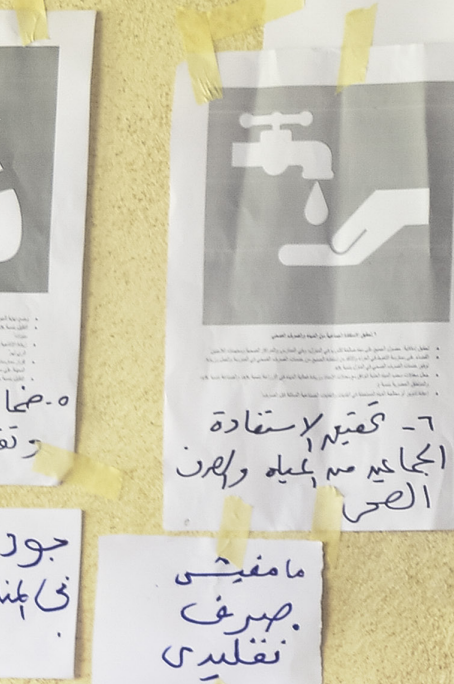

Y Yvís - 7 gel

Sil

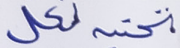

(i)

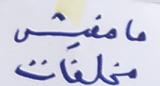
sLi

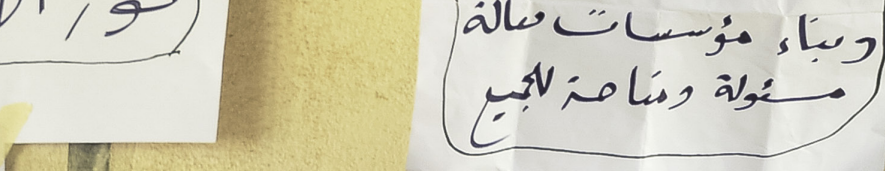

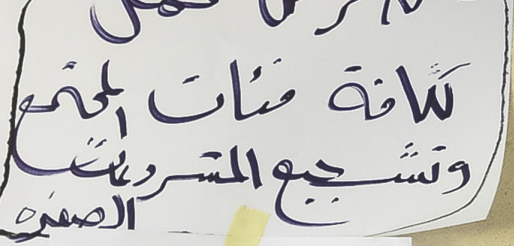

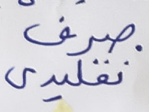

is

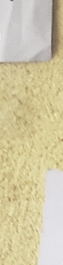

Policy
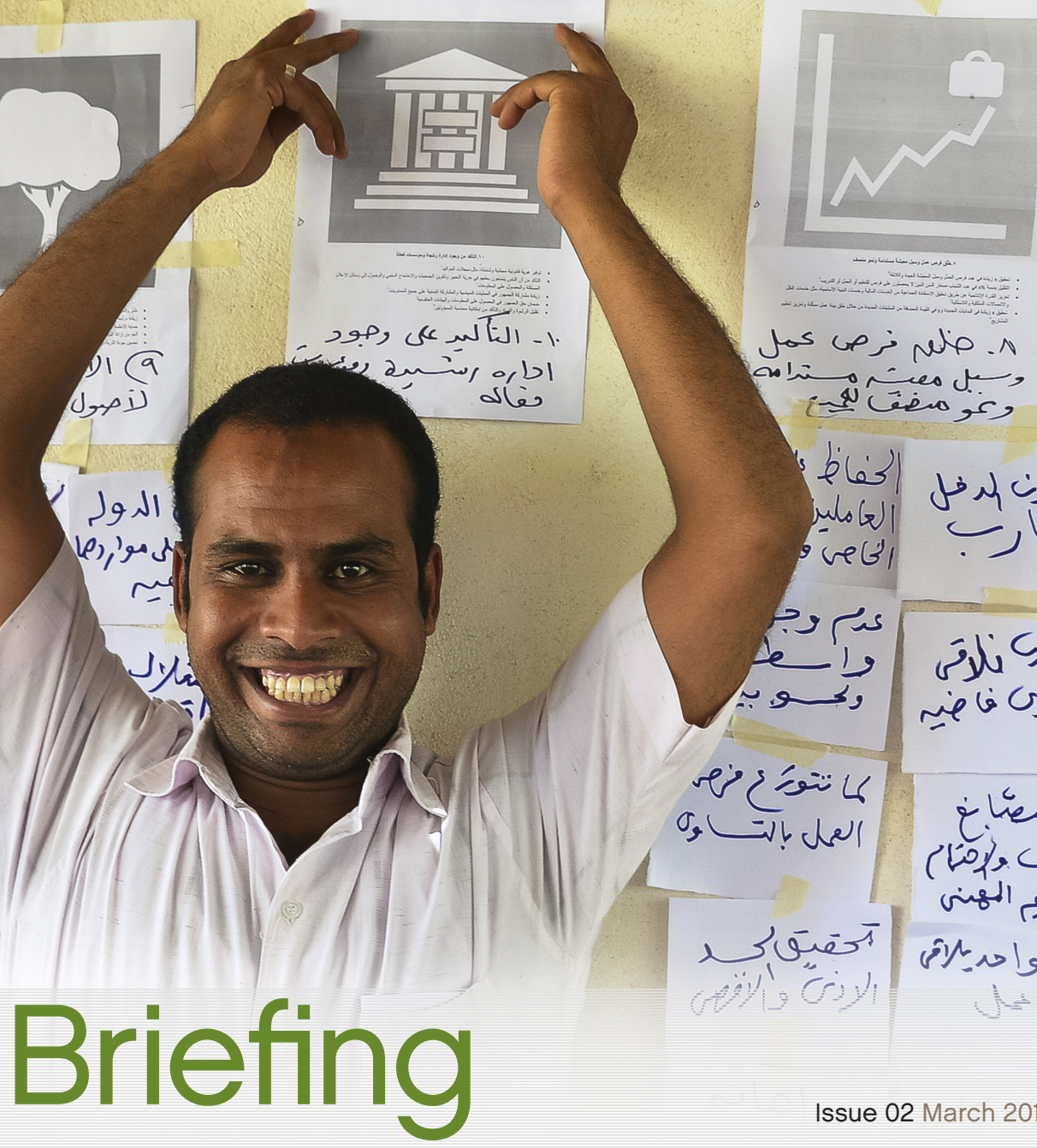

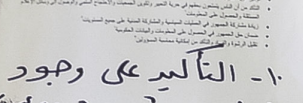

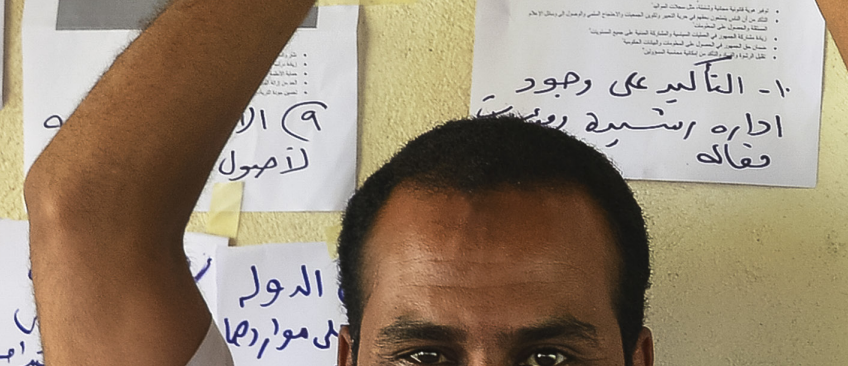

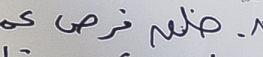

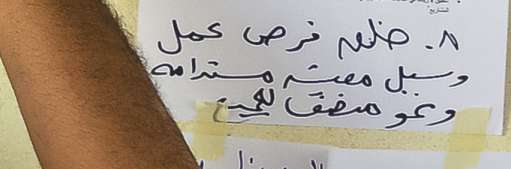

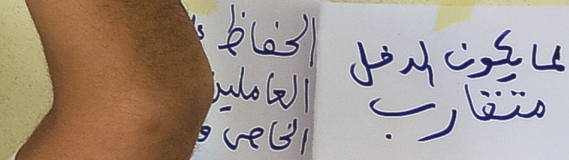

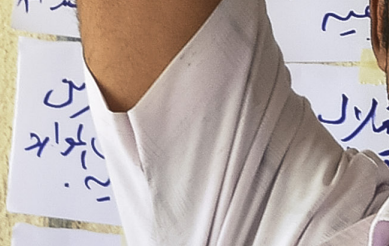

(tors

N

.

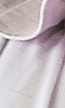

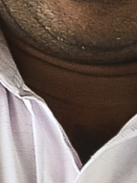

\title{
Achieving meaningful accountability for people living in poverty and marginalisation
}

Meaningful accountability can shift power imbalances that prevent sustainable development for people living in poverty and marginalisation. Accountability consists of both the rights of citizens to make claims and demand a response, and the involvement of citizens in ensuring that related action is taken.

However, for the poorest and most marginalised people accountability is often unattainable. They face multiple barriers in influencing social, political and economic decision-making processes and accessing the services they are entitled to.

This briefing draws on research by the Participate initiative to highlight the key components necessary for processes of accountability to be meaningful for all:

\section{- Accountability needs to be understood} as a systemic issue that is not just about the relationship between citizen and state, but about the multiple lines of accountability between diverse actors and institutions, including the private sector, and institutions that shape social norms such as religious bodies and civil society organisations.

\section{- Making accountability meaningful means} addressing the exclusion and discrimination that can define people's experience of citizenship.

- Claiming identity is a critical starting point for establishing channels of accountability When people living in poverty and marginalisation are able to value and express their own identity as citizens and create space for freedom of voice and association, the possibility of collective actions toward social justice becomes real. It is in this process that citizens begin to construct and shape spaces and channels of accountability.
Above

Participant in a Ground Level Panel, Egypt. PHOTOGRAPH: CDS 2013

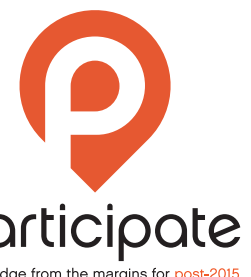

Web

www.participate2015.org

Email

participate@ids.ac.uk

Twitter

@participate2015 


\section{Claiming identity is critical for accountability}

When people experience stigmatisation, persecution and social exclusion as a result of socially constructed identities, their experience of citizenship is curtailed and they are forced to live in the margins. When their identities are not recognised by the dominant legal and social institutions, they have little recourse to formal structures of citizenship including the protection of law. This applies to many different types of identities, including ethnic minorities who are not recognised by the state, people who are not legally registered at birth, refugees, transgender people whose gender identity is not formally acknowledged, for example on legal documents.

However, when they come together to construct their own identities as citizens, they make an important step towards transforming their 'excluded' status. By coming together, they can build horizontal relationships with other citizens which support their feelings of inclusion, belonging and equality. They can collectively learn about their rights and begin to articulate their individual and collective claims to those rights.

\section{Citizen engagement, group formation and collective action for accountability}

Accountability relationships require citizens to engage with decision-making institutions to claim their rights. The capacities and confidence needed for this can be built through group formation and collective action. There are a variety of ways in which this was achieved:

- Identity-based group formation

- Extending solidarity across exclusion and inequality, and recognising how people's multiple identities intersect

- Communal self-provisioning to secure livelihoods and wellbeing

- Coming together to address a specific issue that affects the whole community, such as resource extraction

Trying to achieve accountability without investing in sustainable and democratic group formation risks leaving poor and marginalised people exposed to the power of local elites who claim legitimacy on behalf of local constituencies but who often do not have it. A range of mechanisms have been developed by social movements, opposition groups, participatory development practitioners and some governments to support such group formation. Creative learning approaches such as storytelling and theatre, for example, have been shown to be powerful tools in supporting citizens to surface issues, analyse them, and mobilise around them. Within the Participate initiative, Ground Level Panels facilitated by civil society organisations in Brazil, Egypt, India and Uganda were developed as one approach to bring a diverse range of marginalised peoples into dialogue. These included, for example, internally displaced people, transgender people, and people living in extreme poverty in urban slums and isolated villages. Through deliberative and participatory approaches these citizens proposed principles for the post-2015 international development framework which contested proposals made within the formal deliberations of the UN.

\section{Challenging systemic and institutional discrimination}

Global normative frameworks and human rights agreements play a critical role in shaping legislation at the national and local level. Where these frameworks have local ownership they are integral to challenging institutional discrimination and power imbalances that marginalise different groups of citizens.

However, for the poorest and most marginalised people, laws and policies at all levels rarely translate into the realisation of rights.

- This disconnect relates to contextual and discriminatory social norms that are deeply embedded in institutions that mediate access to services and realisation of rights.

- Where a person's rights have been violated, discrimination, corruption and high transaction costs prevent marginalised groups accessing justice.

- In the case of socially marginalised identities (such as LGBTQI) legal recognition 《When people come together to construct their own identity as citizens, they make an important step towards transforming their 'excluded' status. $\boldsymbol{~}$ through changes in identity cards does not automatically lead to respect and inclusion in their lived realities. People may still experience discrimination and exclusion, often violently.

Making this gap between legislation and reality visible is critical. For accountability to be meaningful, citizens need to be engaged with policymakers in both the creation, implementation, and monitoring of laws, policies and programmes. Organised citizen groups are taking action to hold government programmes to account for reaching more marginalised people, and also acting as a platform for marginalised people to enter government schemes to claim their entitlements: 


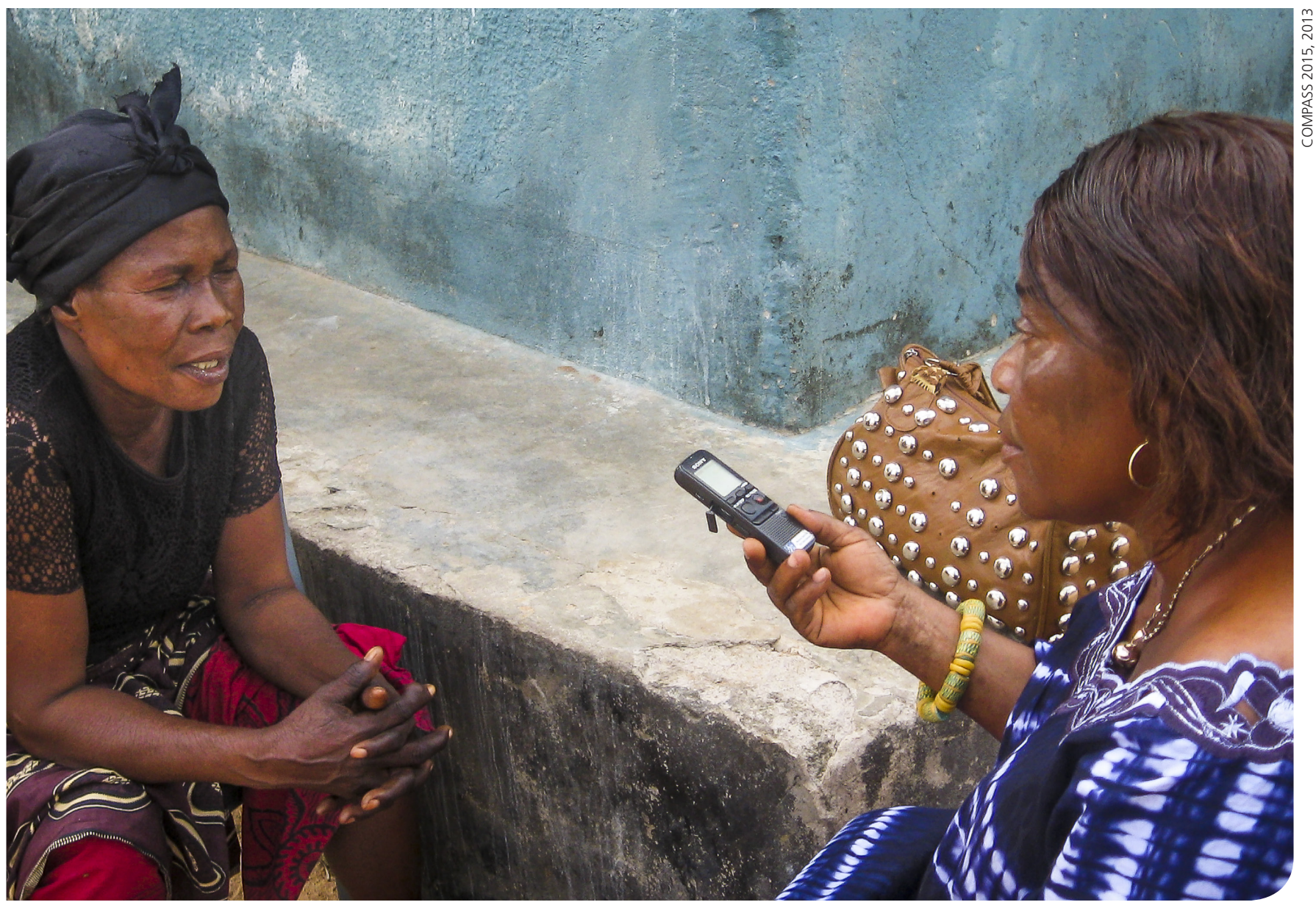

- In Bangladesh, community-based organisations are playing an important role in ensuring that government development committees include diverse and inclusive groups of older people and people with disabilities in their constitution.

- In India, education on rights and entitlements by NGOs has accompanied group-building processes for sexual minority persons and the resulting advocacy has broken down barriers to access in government social protection schemes.

\section{Securing private sector accountability in complex contexts}

People living in poverty and marginalisation are living in extremely insecure and isolated contexts, often distant from formal accountability relationships. It is often not clear who should be held to account, as diverse public and private actors influence and shape processes of social change. The role of the private sector in development has blurred the boundaries of accountability making it harder for ordinary people to know how to engage. The power and resources of these private institutions deepens the imbalance experienced by people on the margins.
In these contexts there is a lack of political will among governments to implement regulatory frameworks, and policies often favour economic development agendas over the rights of citizens.

Demanding accountability can therefore be dangerous and can lead to, sometimes violent, clashes. Political elites may face co-option as corporations work to legitimise their activities. The efforts of citizens' collectives, civil society organisations (CSOs) to challenge these exclusionary dynamics therefore need to be strengthened:

- CSOs need to be engaged as intermediaries between marginalised citizens and powerholders. Co-option must be addressed to ensure that different political representatives are amplifying citizens' voices.

- Solidarity between community organisations is crucial. In the Philippines, a women's association and youth groups in one community supported the Indigenous Peoples' Organisation to claim rights against extractive industries.

Networked approaches that engage multiple actors across citizen, civil society, state, and private sectors in the process of accountability could bring together diverse knowledge sets, strengthen relationships and build momentum for change. 
I tell you this: unity is strength. There doesn't have to be anyone in charge, all together we can be in charge because we are fighting for the same goal. If you are fighting for the same goal, then what happens? You'll use your wisdom and the others will use theirs. Because your knowledge is your knowledge. One learns from the other, one helping the other.

(Brazilian research participant; ATD Fourth World 2013, in Burns et al. 2013)

\section{Policy recommendations}

The following recommendations reflect the interconnected roles and responsibilities between institutional actors, citizens and civil society intermediaries within sustainable relationships of accountability. At the centre of these partnerships processes of change must be driven by the rights claims of marginalised citizens.

\section{To governments}

- Recognise citizens as key actors in their own development and commit to citizen participation at every stage of policy and programme cycles. One approach to listening and engaging with citizens is to identify key pathways through which their voices feed into and have impact on government and private sector policy.

- Address the barriers to people living in poverty and marginalisation having control over assets and resources they are entitled to. They should ensure legal status that recognises diverse and marginalised identities and enable people in these groups to advance rights claims.

- Allocate resources to support enabling environments for civil society and citizens to interact, organise, and associate safely and freely.

- Support inclusive and dialogic approaches that enable learning across experiences between citizens and support the empowerment of marginalised groups for such participatory commitment to be meaningful.

- Support and enforce laws and regulatory frameworks that hold public and private institutions to account on citizens' rights claims.

\section{To civil society organisations}

- Work with citizens to understand barriers to access in service provision, and develop strategies with citizens and governments to drive cultural change that promotes inclusivity and responsiveness.

- Support citizens to analyse the socio-political contexts in which collective action is evolving to mitigate against backlash and reprisal for already marginalised groups.

- Focus efforts on supporting citizens at ground level to raise their voices. This includes working in longer-term partnerships to build the sustainability of groups mobilising for change.
Further reading

Burns, D.; Lopez-Franco, E.; Shahrokh, T. and Ikita, P. (2015) Citizen participation and accountability for sustainable development, Brighton: IDS.

Burns, D.; Howard, J.; Lopez-Franco, E.; Shahrokh, T. and Wheeler, J. (2013) Work with us: How people and organisations can catalyse sustainable change, Brighton: IDS.

Lopez-Franco, E. and Shahrokh, T (2013) Bringing ground level experiences to the post-2015 global development process, Brighton: IDS.

All available at:

www.participate2015.org/ resources

\section{Authorship}

This policy briefing was written by Thea Shahrokh and Erika Lopez-Franco from the Institute of Development Studies (IDS) with substantial contributions by Fellows, Danny Burns and Jo Howard, and edited by Emilie Wilson. It is based on findings from participatory research contributing to the Participate initiative, which aims to provide high quality evidence on the reality of poverty at ground level, bringing the perspectives of the poorest into the post-2015 debate.

The opinions expressed are those of the authors and do not necessarily reflect the views of IDS or Beyond 2015. Readers are encouraged to quote and reproduce material from Participate Policy Briefings. Participate requests due acknowledgement and quotes to be referenced. 